\title{
Development of Optimal Work Pattern Framework for Malaysian Construction Workers
}

\author{
Siti Hafizan Hassan”, Mohd Samsudin Abdul Hamid, Nur Izzyanie Zainal, Zulfairul Zakariah, \\ Nurulzatushima Abdul Karim, Adhilla Ainun Musir
}

Faculty of Civil Engineering, Universiti Teknologi MARA Cawangan Pulau Pinang, 13500, Permatang Pauh, Pulau Pinang, Malaysia

Received January 10, 2021; Revised July 27, 2021; Accepted August 9, 2021

\section{Cite This Paper in the following Citation Styles}

(a): [1] Siti Hafizan Hassan, Mohd Samsudin Abdul Hamid, Nur Izzyanie Zainal, Zulfairul Zakariah, Nurulzatushima Abdul Karim, Adhilla Ainun Musir, "Development of Optimal Work Pattern Framework for Malaysian Construction Workers," Civil Engineering and Architecture, Vol. 9, No. 5A, pp. 19 - 32, 2021. DOI: 10.13189/cea.2021.091303.

(b): Siti Hafizan Hassan, Mohd Samsudin Abdul Hamid, Nur Izzyanie Zainal, Zulfairul Zakariah, Nurulzatushima Abdul Karim, Adhilla Ainun Musir (2021). Development of Optimal Work Pattern Framework for Malaysian Construction Workers. Civil Engineering and Architecture, 9(5A), 19 - 32. DOI: 10.13189/cea.2021.091303.

Copyright $\bigcirc 2021$ by authors, all rights reserved. Authors agree that this article remains permanently open access under the terms of the Creative Commons Attribution License 4.0 International License

\begin{abstract}
Currently, the country's unpredictably high temperatures are major source of concern for outdoors workers. Because this element has the potential to affect worker productivity, research into both working time and temperature becomes a great interest. Aside from that, both factor studies will determine the best work schedule for construction workers to avoid heat stress. The investigation was completed using two methods: interviewing and site observation. The optimum recipe for worker productivity was discovered during the interview by the site specialist. After obtaining the correct formula, a site inspection was carried out. During the site observation, a few variables were recorded, including average temperature, working time range, and worker output for three different types of work: bar bending, rebar wall installation, and tile installation. The effect of heat stress on three types of work is investigated. Then there was a comparison of worker productivity in two different sorts of jobs. Based on the findings, the best working pattern has been identified. Then there was a comparison of worker productivity in two different sorts of jobs. The best working pattern that adds the most to worker productivity was discovered as a result of the investigation. Finally, obtaining the requirements for a successful project as well as an optimal work pattern achieves both objectives.
\end{abstract}

Keywords Heat Stress, Work Pattern, Construction Work

\section{Introduction}

Climate change has resulted in an increase in the frequency and intensity of extreme temperatures during the last decade [1]. Construction workers are frequently exposed to these high-temperature trends when working in a hot environment. Working in hot situations can cause people to become stressed and tired, which can lead to major health problems due to dehydration and weariness. Dehydration and weariness can cause bodily disturbances when this stress is paired with physical activities. Employees in the construction industry have traditionally had a substantially higher risk of work-related illnesses and accidents than workers in other industries or the public sector [2]. This is caused by working in hot conditions or a high level of heat stress in the atmosphere. Heat stress is a type of physical danger contributed by extreme heat that can harm a workers' health either directly or indirectly. Exposure to extreme heat can result in occupational illnesses and injuries. Heat waves also have an impact on employee health and productivity [3]. These concerns are related to a study looking into the link between heat stress and worker productivity over the course of a working day. The Malaysia Productivity Blueprint, which was launched on May 8, 2017 in Putrajaya by Prime Minister Datuk Seri Najib Tun Razak, established a minimum aim of 3.7 percent annual worker productivity growth by 2020 . He also writes to the appropriate ministry, agency, and private sector to inform 
them about the plan and what they should do to meet the deadline. According to his speech, he believes that increasing worker productivity will boost the country's overall productivity.

Furthermore, Malaysia's economy will become more competitive and create higher growth as a result of increased productivity. As a result, a research of the factors impacting worker productivity must be conducted in order to boost worker productivity. One of the studies looking into the influence of heat stress on worker productivity is this one. These studies that are conducted also looks into the influence of heat stress on worker's productivity as a part of it. New working time can be generated as a result of this research. The investigation continued using the generated analysis line graph to see how heat stress affected three different categories of worker workers: tile installers, wall reinforcement bar installers, and bar benders. To establish a link between heat stress and worker productivity, this type of analysis was carried out using Excel tools. Finally, it was designed to improve and lessen reduce the effects of heat stress on workers, hence increasing worker productivity and project performance. The nearest location will be given the recommendation for an optimal work pattern in order to increase project quality by increasing worker productivity.

\section{Methodology}

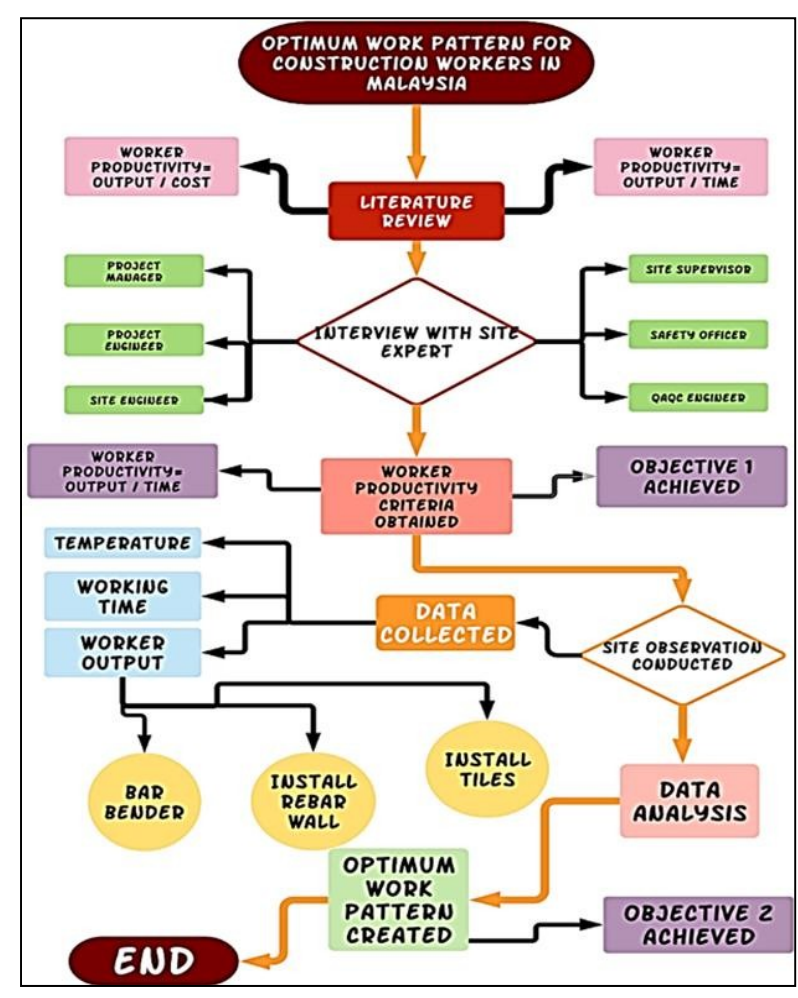

Figure 1. Research Methodology

The methodology is divided into two sections. First, information gathered from a literature review of pertinent books, journals, papers, and previous theses. The information was gathered through an interview and a site visit to one of the chosen locations. Figure 1 depicts the technique flow throughout this study. The data collection began in March 2019 and continued until September 2019, when all of the information needed to meet the goal was gathered.

\subsection{Literature Review}

A literature review was carried out in order to gain a better grasp of prior research, books, journals, articles, and theses. Aside from that, the literature review can identify research that isn't being investigated. Literature review, according to [4] displays the ability to generate new research. The literature review also reveals the research deficit. In this study, all of the associated terms were discovered in the previous study, and the interviewees picked the criteria for worker productivity.

\subsection{Site Expert Interview}

The majority of the interviewees in this study are industry veterans, such as Project Managers, Project Engineers, Site Engineers, Site Supervisors, Safety and Health Officers, and Quality Assurance/Quality Control Engineers. The data are examined based on the majority viewpoint and the interviewees' perspectives on the case study data. Furthermore, the interview was conducted to determine the best appropriate formula for calculating worker productivity based on each interviewee's prior experience. The formula presented to the interviewers was gathered through the literature evaluation process for a previous study. The goal of the interview process is to get the site experts' input on the criteria for worker productivity.

\subsubsection{Interview Question Design}

To make the interview process go more smoothly, the planning to construct an interview question was done in advance to ensure that no information was missing. The question is built around the research's two objectives. The top two formulas from the previous research will be included in the question to design the work pattern of productivity in goal two, and one of the formulae chosen by the interviewees will be the main formula to calculate worker productivity. As stated in Table 1, the interview session is separated into different parts in order to acquire as much information as possible. The interview is done with the site organization manager.

Table 1. Session of interview

\begin{tabular}{cc}
\hline Type of workers & Working Pattern \\
\hline Bar Bender & $8: 30 \mathrm{am}-10: 00 \mathrm{am}$ \\
Installation rebar wall & $11: 00 \mathrm{am}-12: 30 \mathrm{pm}$ \\
Installation tiles & $1: 30 \mathrm{pm}-3: 00 \mathrm{pm} 4: 00 \mathrm{pm}-5: 30 \mathrm{pm}$ \\
\hline
\end{tabular}




\subsubsection{Interview Session}

Session 1, Session 2, and Session 3 comprised the four sessions of the interview. The first session of the interview is used to gather demographic information about the interviewees and their company. This session comprises five questions: their title, length of experience, principal business nature of the organisation, year of operation, and class.

Session 2 is a session in which the interviews' awareness of productivity is gauged by inquiring how the interviewees measure worker productivity. Based on their experience and awareness of heat stress in Malaysia, the question was expanded to include the most important elements that influence worker productivity.

The respondents are questioned about their concerns on factors that affect worker productivity in the last session, and they must pick between two formulas from prior research that are applicable to measuring worker productivity throughout this study.

\subsubsection{Site Observation}

Three categories of personnel are being chosen based on the site's existing progress. During the site visit, the work in progress included bar bender work, rebar wall installation, and tile installation. The site observation process will last one month, starting on August 1st and ending on August 31st.

Workers' output, temperature, and working pattern were used to produce the line graph analysis to see the influence of heat stress on worker productivity. Table 2 shows the working routine for each day, which is divided into four equal sections: 8:30am-10:00am, 11:00am-12:30pm, 1:30pm-3:00pm, and 4:00pm-5:30pm.

Worker output is determined by the number of steel bends made by the bar bender, the area of a rebar wall installed, and the number of tiles installed. Weather Live: Weather Forecast \& Alerts, an Apalon application, records the temperature.

Table 2. Site observation data collected

\begin{tabular}{|c|c|}
\hline Session & Description \\
\hline 1 & General information of the respondent. \\
\hline 2 & $\begin{array}{l}\text { The awareness of worker productivity, factors } \\
\text { affecting worker productivity and heat stress. }\end{array}$ \\
\hline 3 & Formula to calculate the worker productivity \\
\hline
\end{tabular}

\subsubsection{Data Analysis}

According to Table 3, the analysis of the data for the study was separated into two approaches, both of which were analysed using Excel tools for all of the interviewees' results. One of the objectives will be met as a consequence of this analysis, which is the criterion for worker productivity based on the results chosen by the respondents.

After the worker productivity was determined, the site observation was performed to investigate the time, temperature, worker numbers, and worker output. Worker productivity was evaluated using three different kinds of work based on the data collected. Furthermore, the analytical procedure continued with the creation of a line analysis graph using Excel tools to see the impact of heat stress on three different categories of workers: tile installers, wall reinforcement bar installers, and bar benders. To establish a link between heat stress and worker productivity, this type of analysis was carried out using Excel tools. The optimal work schedule for each type of activity is determined when the association between heat stress and worker productivity is established.

Finally, the prescription to boost worker productivity is presented in order to lessen the impact of heat stress on workers, hence increasing worker productivity and project performance.

Table 3. Type of Data Analysis

\begin{tabular}{cc}
\hline $\begin{array}{c}\text { Objective 1: Interview } \\
\text { Analysis }\end{array}$ & Excel tools - Graphical analysis \\
\hline $\begin{array}{c}\text { Objective 2: Site } \\
\text { Observation } \\
\text { Analysis }\end{array}$ & Excel tools - Line graph analysis \\
\hline
\end{tabular}

\section{Result and Discussion}

\subsection{Data Collection}

The study's focus is on a construction site in Condominium Site in Pulau Pinang, where 300 condominium apartments are being built as part of a development project. There are a total of six interviewees, each with a distinctive designation. Project managers, project engineers, site engineers, site supervisors, and quantity assurance/quality control engineers make up the majority of them. To make the evaluation of the interviews' opinions easier, all of the questions answered by the respondents were turned to data. Following that, all of the data will be examined, and the best criteria will be developed. The data collection was then supplemented with on-site observations of the impact of heat stress on worker productivity. The output of workers is measured four times a day to calculate their productivity. Aside from measuring worker production, the current temperature is collected at each time interval.

\subsection{Interview Analysis}

The frequency analysis was carried out in order to determine the proper criteria for calculating worker productivity. If all of the conditions for a worthwhile venture are met, the goal project is archived.

\subsubsection{Interview with Respondent 1 (Project Manager)}

The first interview was done with a project manager with more than 11 years of construction industry expertise. 
He has worked in a variety of building businesses.

$\mathrm{He}$ is very concerned about worker productivity but has also measured it in order to improve the project's success. Aside from that, he acknowledged that the weather, bad planning, and communication skills can all have an impact on worker productivity. He acknowledged that he was unaware of the heat stress that workers endure and that companies should be concerned about the effects of heat stress. According to him, the company's operating hours are $8: 30$ p.m. to $5: 30$ p.m. He was given the option of choosing between worker output per unit time and worker output per unit worker cost as worker productivity criterion, and he chose to measure worker productivity using the formula worker output per unit time.

\subsubsection{Interview with Respondent 2 (Project Engineer)}

The project engineer is now working at the construction site in Permatang Pauh, Pulau Pinang. He has worked in the construction industry for more than 7 years. He has worked in a variety of construction businesses, the most notable of which being bridge construction.

$\mathrm{He}$ is concerned about worker productivity, but he has no way of measuring it, and he is still unaware of the heat stress that the workers are experiencing. Aside from that, he acknowledged that weather, bad planning, and overtime can all have an impact on worker productivity.

According to him, any factors affecting worker productivity should be of concern to the existing organisation. He agreed that companies should be aware of the impact of heat stress on employees, and he also acknowledged that the industry is unaware of the issue. Finally, he intends to calculate worker productivity using the formula worker output per unit time vs. cost.

\subsubsection{Interview with Respondent 3 (Site Engineer)}

A recent civil engineering graduate who is currently working on a condominium project. His building site experience isn't as extensive as others'. He's just been working on construction sites for a year, and the condominium is his first job.

$\mathrm{He}$ is really concerned about worker productivity, yet he does not even know how to quantify it. It is because this is his first year in the building sector. Aside from that, he stated that various elements, such as weather, overtime, and communication skills, can affect worker productivity.

According to him, any factors affecting worker productivity should be of concern to the existing organisation. He agreed that companies should be aware of the impact of heat stress on employees, and he also acknowledged that the industry is unaware of the issue. He intends to use the formula worker output per unit cost to measure worker productivity.

\subsubsection{Interview with Respondent 4 (Site Supervisor)}

The condominium project's site supervisor has more than 11 years of expertise in the building sector.
$\mathrm{He}$ is concerned about worker productivity, but he has yet to assess it and is unaware of the heat stress that the workers are experiencing. Aside from that, he stated that various factors, such as weather, safety, and overtime, can affect worker productivity. He agreed that companies should be aware of the impact of heat stress on employees, and he also acknowledged that the industry is unaware of the issue. He intends to use the formula worker output per unit time to measure worker productivity.

\subsubsection{Interview with Respondent 5 (Safety Officer)}

The Safety Officer has worked in the construction business for 5 years. He was concerned about all the issues that affect the workers' health and the site's condition because he was designated as the safety officer. $\mathrm{He}$ is also mindful of the dangers of heat stress to their employees' health.

He is deeply concerned about worker productivity, but he lacks the ability to assess it due to his sector of work. Aside from that, he stated that various factors, such as weather, safety, and overtime, can affect worker productivity.

He also feels that companies should be aware of the impact of heat stress on employees, and he agrees that the sector is currently unaware of the issue. Finally, he opts for a per-unit-time calculation of worker productivity. He also stated that because all workers originate from a variety of nations with varying costs, the criteria used to calculate worker production per unit cost are insufficient.

\subsubsection{Interview with Respondent 6 (QAQC Engineer)}

The last responder, who works for Anas Construction Sdn. Bhd. as a QAQC Engineer, is the only female among the respondents, but she has roughly 4-years of experience in the construction business.

She is concerned about worker productivity, but she has yet to assess it and is unaware of the heat stress that the workers are experiencing. Aside from that, he agreed that various elements, such as weather, overtime, and motivation, can affect worker productivity.

Finally, she intends to use the formula worker output per unit time to determine worker productivity.

\subsection{Graphical Analysis and Discussion of Interview}

All of the data from the six interviewees were gathered, and the graphical analysis was performed depending on their question and session.

\subsubsection{Session 1: Interviewee's General Information}

\subsubsection{Designation}

There is one project manager, an equal number of project engineer, site engineer, and site supervisor among the responders. Two other interviewees round out the group. One of them is the company's safety and health officer. 


\subsubsection{Interview Experience}

The majority of the interviewees are construction site veterans. According to the data, the interviewees with 11 to 15 years of experience account for 33.33 percent of the total, which amounts to interviewees with 3 to 5 years of building site experience. Furthermore, interviewees with 6 to 10 years of experience and those with less than 3 years of experience both had the same rate of 16.67 percent.

\subsubsection{Session 2: Awareness}

\subsubsection{Worker Productivity}

The interviewees are asked if they are concerned about productivity. As seen in Figure 2, they are all concerned about worker productivity and answer yes to the question. Worker productivity, according to respondents, is one of the most crucial factors in the project's success.

Despite the fact that all respondents are concerned about worker productivity, the majority of respondents still have not tested worker productivity. The majority of respondents have not tested their worker productivity yet, as seen in Figure 3. This situation demonstrates that practically all of the organization's employers or high-ranking officials have been oblivious to the importance of worker productivity. The reasons for this circumstance could be related to a lack of exposure to worker productivity standards in order to improve the project's performance.

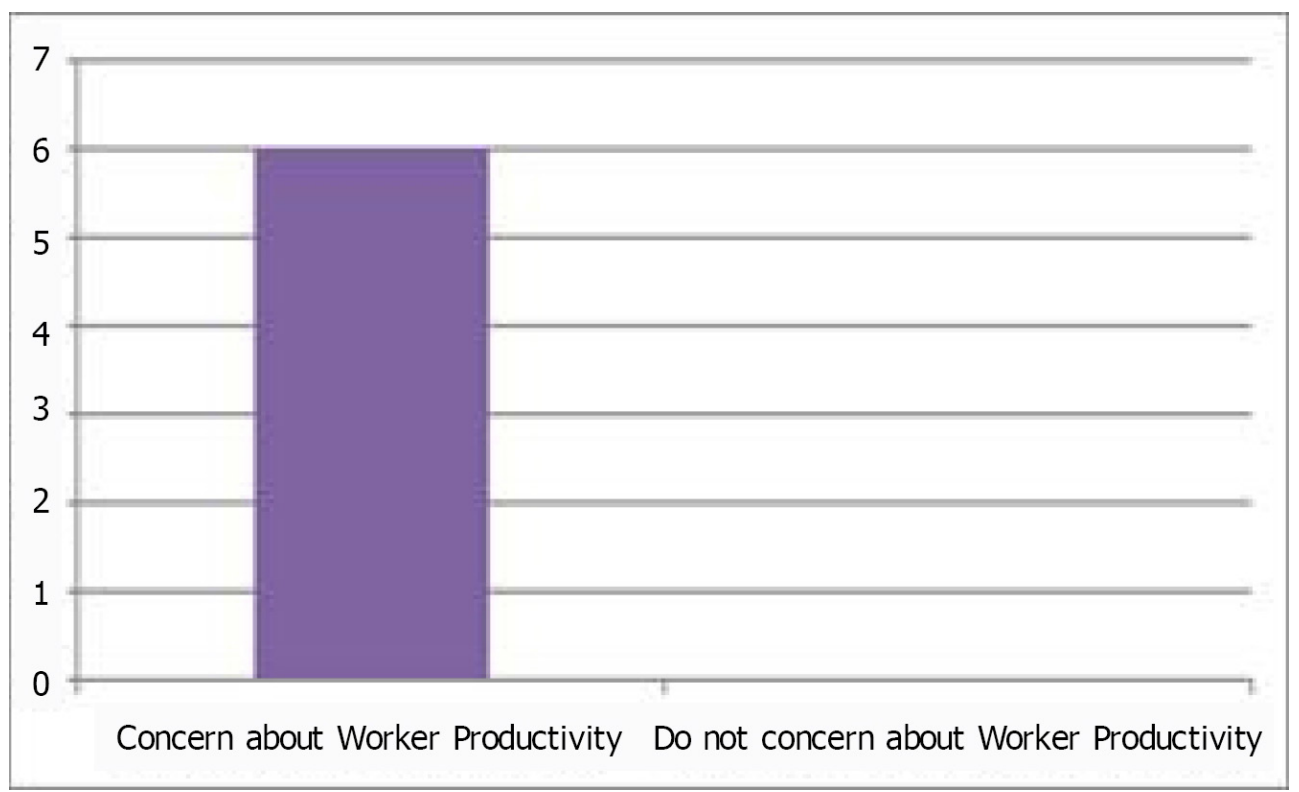

Figure 2. Concern of respondent about worker productivity

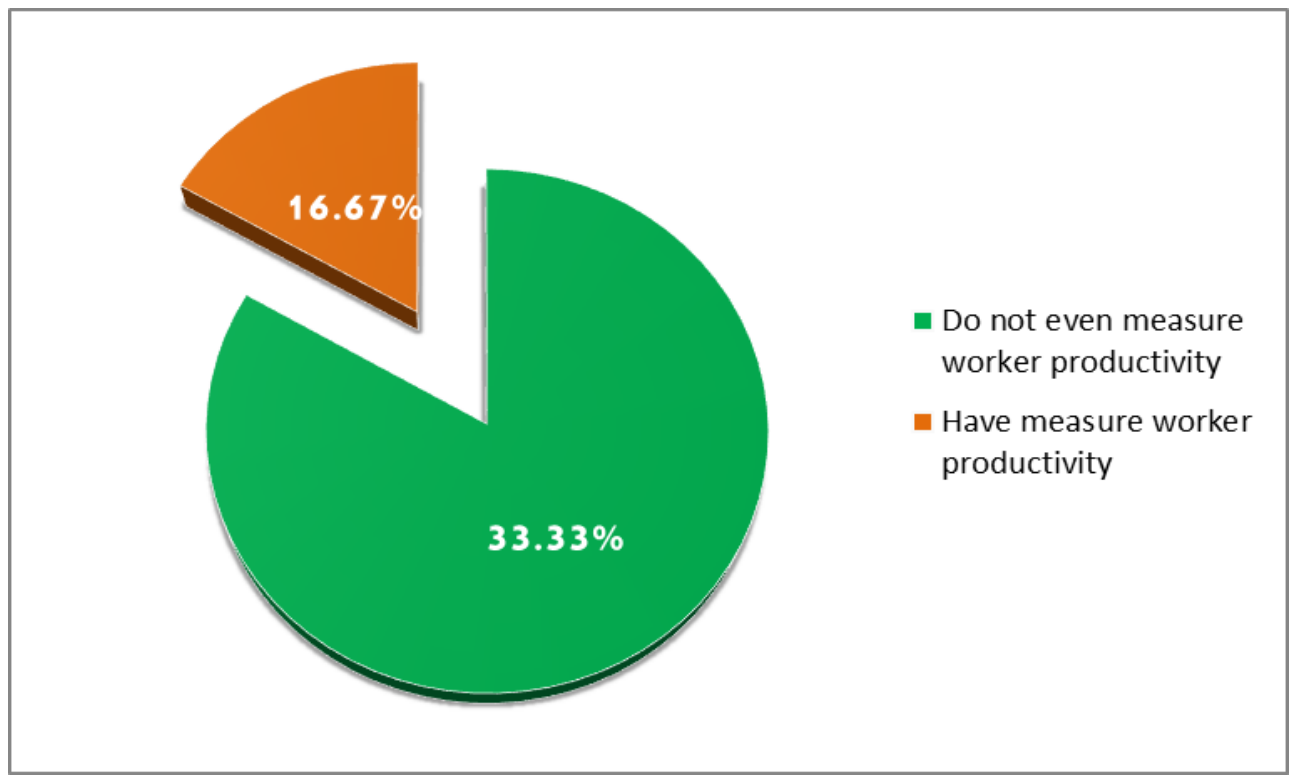

Figure 3. Percentage of respondent measure worker productivity 


\subsubsection{Contribution Factor for Worker Productivity}

Based on the six respondents, the bar chart above depicts the major factors influencing worker productivity. Weather is considered as a greater contribution element that affects worker productivity, according to [5.] As a consequence, this confirms the conclusion that weather is the contributing factor with the most respondents. Furthermore, despite the fact that the weather is an external element, employers cannot disregard it because it is a significant contributor with the biggest number of responders. Next, we'll look at the second component that contributes to overtime. Working overtime may also affect employee productivity. This is owing to the employers' poor provision of rest time. As people can see, extended hours of worker may enhance productivity, but it may also lower the rate of work per time and raise the cost due to the worker's wage per hour. Furthermore, communication skills, safety, and inadequate planning are three contributing factors that have an equal proportion of responses. There are two respondents who consider all of these factors. Finally, one respondent views worker motivation as a contributing element affecting worker productivity.

\subsubsection{Heat Stress Exposure}

Figure 5 shows that four out of six people are aware of heat stress, but two out of six are not. Furthermore, all participants believe that employers should be concerned about heat stress, and that the Malaysian sector is unaware of heat stress, despite the fact that Malaysia is among the countries that is exposed to heat all year, as shown in Figures 6 and 7 .

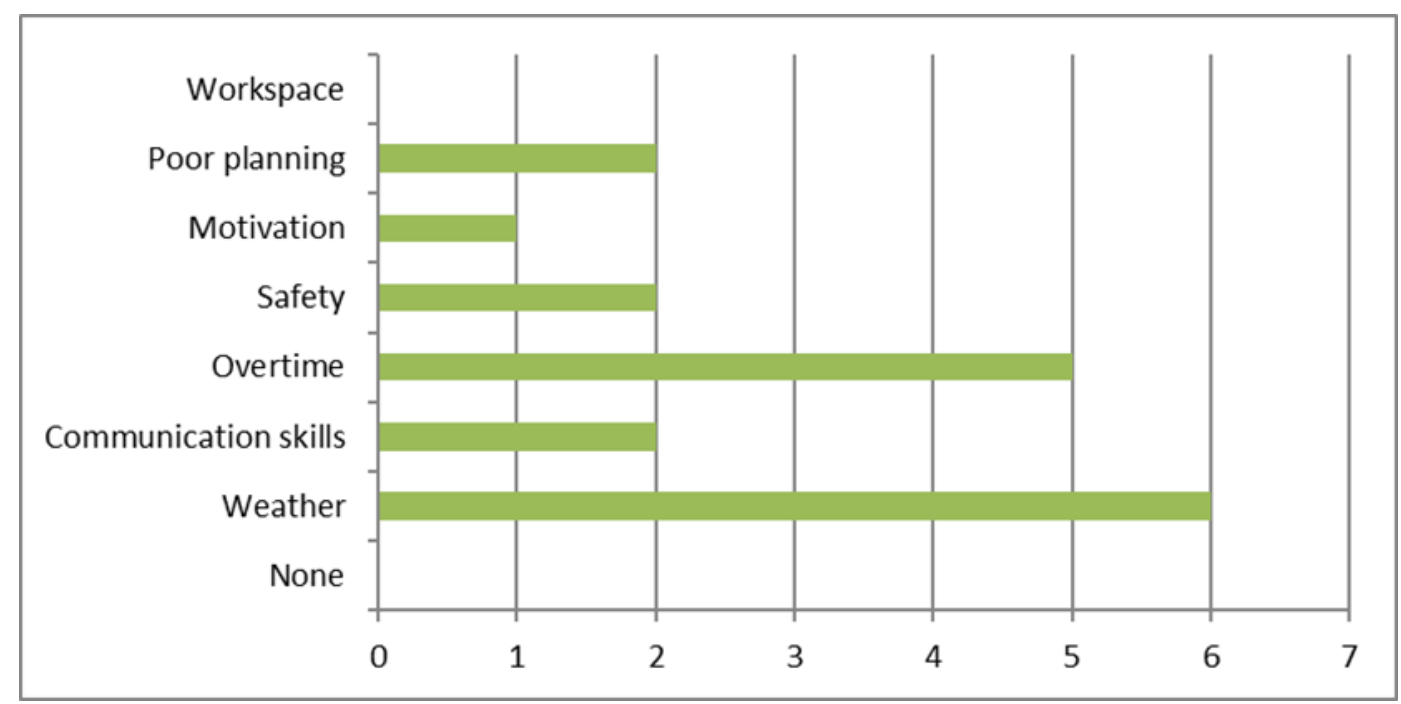

Figure 4. Contribution Factor for Worker Productivity

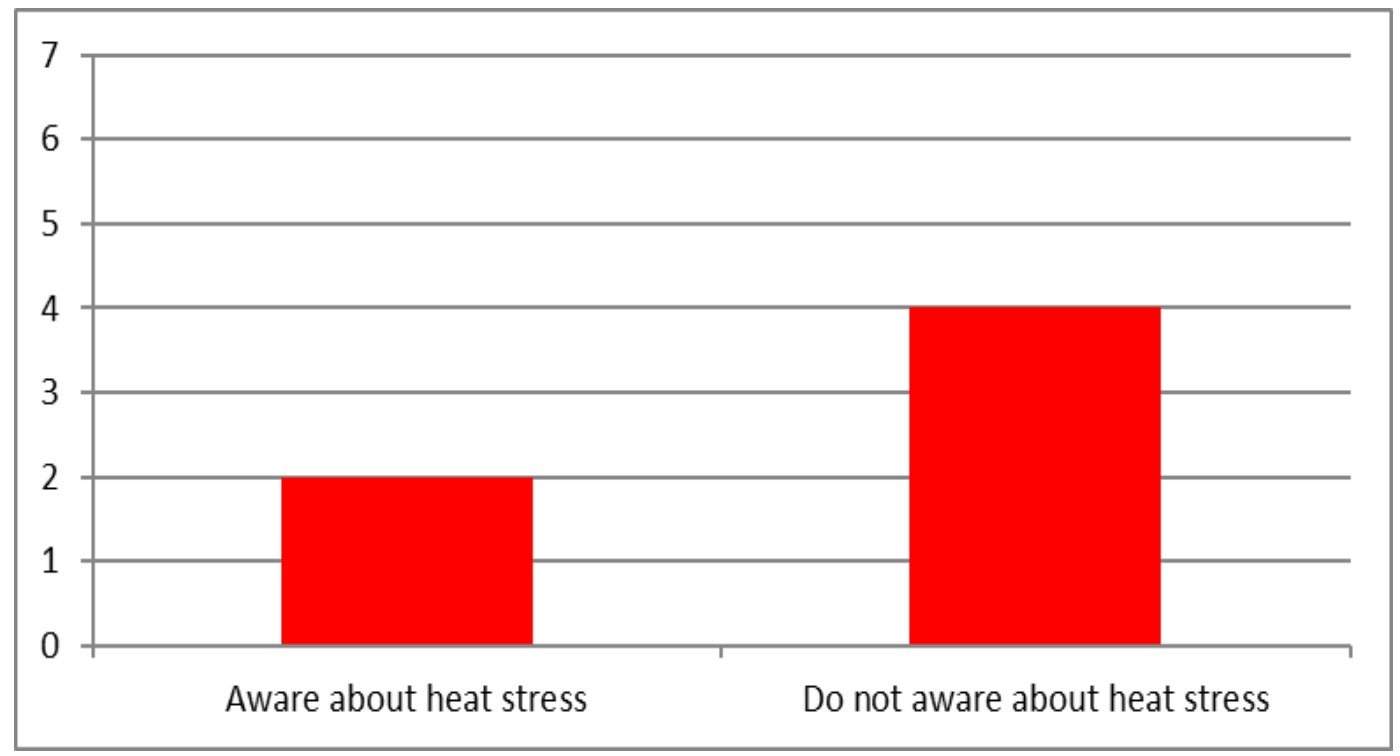

Figure 5. Awareness of respondent regarding heat stress 


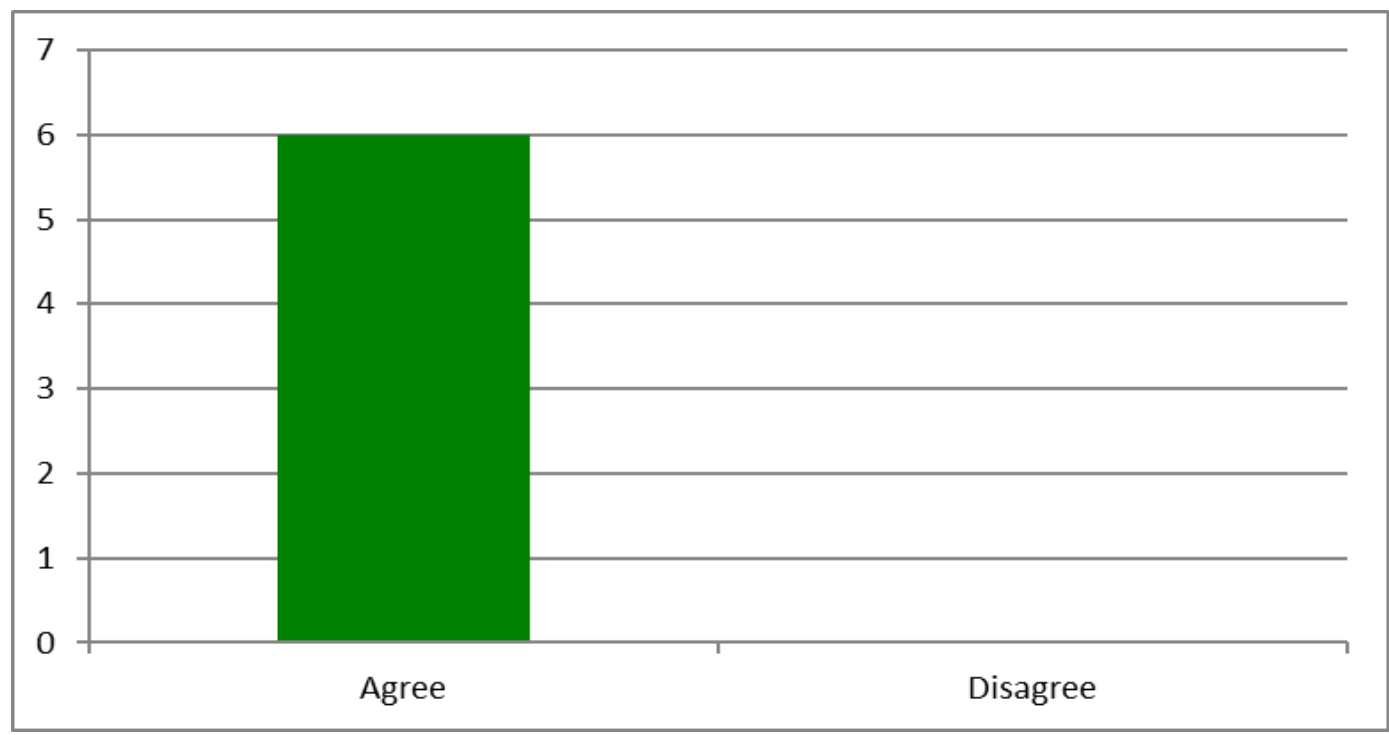

Figure 6. Employers should concern regarding heat stress.

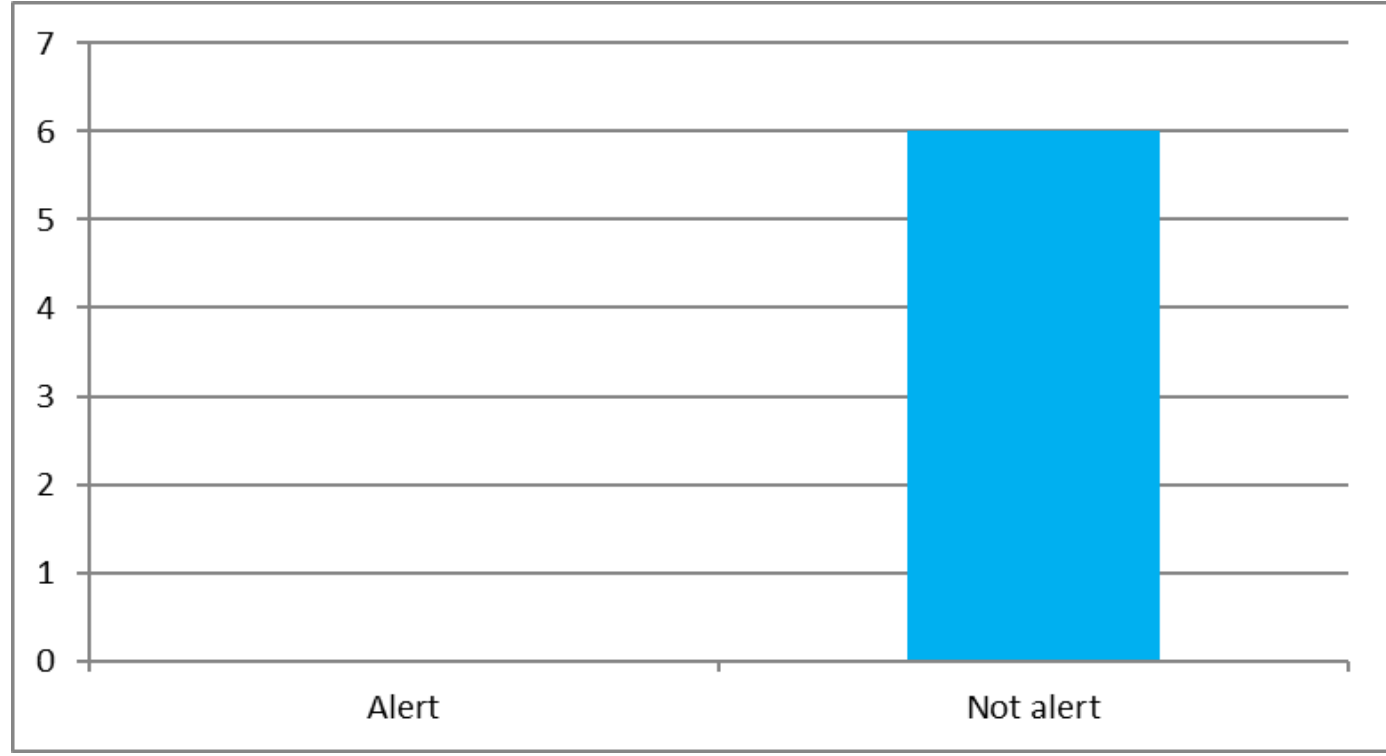

Figure 7. Awareness of industry regarding heat stress

\subsubsection{Session 3: Criteria of Worker Productivity}

\subsubsection{Intention to Measure Worker Productivity}

The respondent is questioned about their objective to gauge productivity in this session. The respondents are questioned about their objective to gauge productivity in this session. The first question in this section is whether employers should monitor productivity and factors impacting productivity, and the fact that every respondent said yes indicates that they should. Furthermore, all of the respondents agreed that employers should be conscious of heat stress when it comes to question number two in the session. The interview then comes to a close with the final question, which is the criterion for a successful project: whether to assess worker productivity based on cost or time to achieve accuracy in evaluating worker productivity. Figure 8 shows that 33.33 percent of respondents agreed to assess worker productivity based on the time-based output of the worker, whereas 16.67 percent prefer to evaluate productivity based on worker costs.

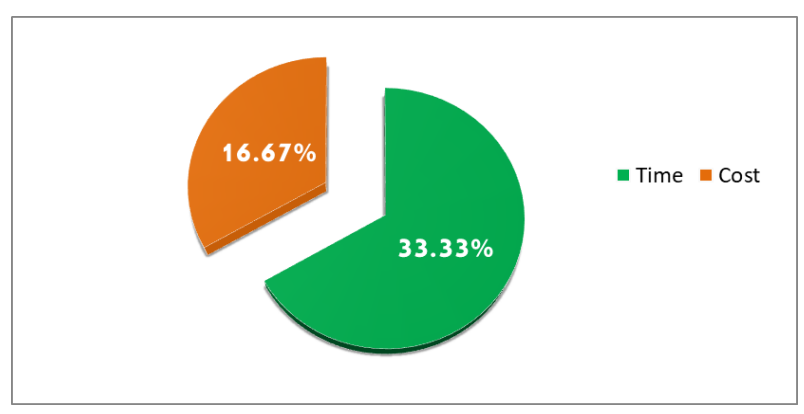

Figure 8. Percentage criteria for worker productivity 


\subsubsection{Discussion}

In economics, productivity is calculated as the proportion of the amount of input to the value of production. It can be used to track technological advancements, economic efficiency, real-time cost control, and manufacturing technologies [6]. As a result, all aspects of productivity must be examined in order to achieve productivity.

As per [7], interviews were conducted to acquire information about people's experiences and attitudes. They also state that the queries were created with the intent of gathering data. As a result, the same technique was used in this study, which was an interview with a site specialist to acquire their perspective. The development of the survey questionnaire is focused on the primary goal of determining worker productivity criteria. The criteria of productivity growth can be measured by worker production per unit hour based on the interview.

\subsection{Line Graph Analysis and Discussion of Site Observation Analysis}

Appropriate worker productivity criteria were derived from the above-mentioned interview study. The parameters for determining worker productivity were used to meet the research's second goal, as indicated below.

$$
\text { Worker Productivity }=\frac{\text { output }}{\text { Time }}
$$

The purpose of site observation is to assess worker productivity. Based on the present development of the site, three categories of work would be evaluated: bar bender work, rebar wall installation work, and tile installation work. The current time's average temperature is also collected in order to investigate the impact of thermal stress on worker productivity.

According to the research, the ideal period for site observation is between 8:30 and 10:00 a.m. Due to increased worker productivity than other time intervals, this time interval was deemed the best work pattern. Working from 11:00 a.m. to 12:30 p.m. exposes you to more heat stress than working from 11:00 a.m. to 12:30 p.m. The most crucial period for worker productivity is between 11:00 a.m. to 12:30 p.m. Finally, a two-time interval evaluates worker productivity in the middle.

\subsubsection{Analysis of the Effect of Heat Stress on Worker Productivity}

Every day, the data are collected as usual. The data were recorded during a 1.5 -hour period, from $8: 30$ a.m. to 10:00 a.m., 11:00 a.m. to 12:30 p.m., 1:30 p.m. to 3:00 p.m., and finally 4:00 p.m. to 5:30 p.m. The average temperature was measured at each time interval to examine how the workers were affected by heat stress.

After that, the workers' output is recorded. The output of the bar bender is calculated based on the number of steel bends, while the output of the rebar wall is calculated based on the square metre of concrete to be installed, and the output of the tile installation is calculated depending on the number of tiles set up. The tiles were put at a dimension of $0.3 \mathrm{~m} \times 0.3 \mathrm{~m}$, resulting in a $0.09 \mathrm{~m} 2$ area per tile. The productivity of workers will be evaluated using (1).

\subsubsection{Bar bender}

The upper and lower worker productivity values are determined. Figure 9 demonstrates that worker productivity peaked at 17.56 n.o.s/hour between 8:30 and 10:00 a.m. on August 31, 2019, at a temperature of 23 degrees Celsius. Furthermore, with a temperature of 32 degrees Celsius on the 4th and 5th of August 2019, the minimal value of worker productivity is 9.33 n.o.s/hour between 11:00 a.m. and 12:30 a.m.

\subsubsection{Installation of rebar wall}

Figure 10 indicated that the higher number of worker productivity was $11.24 \mathrm{~m}^{2}$ /hour between $8: 30$ and 10:00 a.m. on August 16, 2019, at a temperature of 24 degrees Celsius. Furthermore, the minimal value of worker productivity was $5.56 \mathrm{~m}^{2} /$ hour between 11:00 a.m. and 12:30 a.m. on August 31, 2019, with a temperature of 29 degrees Celsius.

\subsubsection{Installation of tiles}

Figure 11 demonstrates that worker productivity peaked at 16.67 n.o.t/hour between 4:00 and 5:30 p.m. on August 2,2018 , at a temperature of 24 degrees Celsius. On the 4 th and 21st of August 2019, with temperatures of 32 and 29 degrees Celsius, the minimal value of worker productivity was 12.67 n.o.t/hour between 11:00 a.m. and 12:30 a.m. 


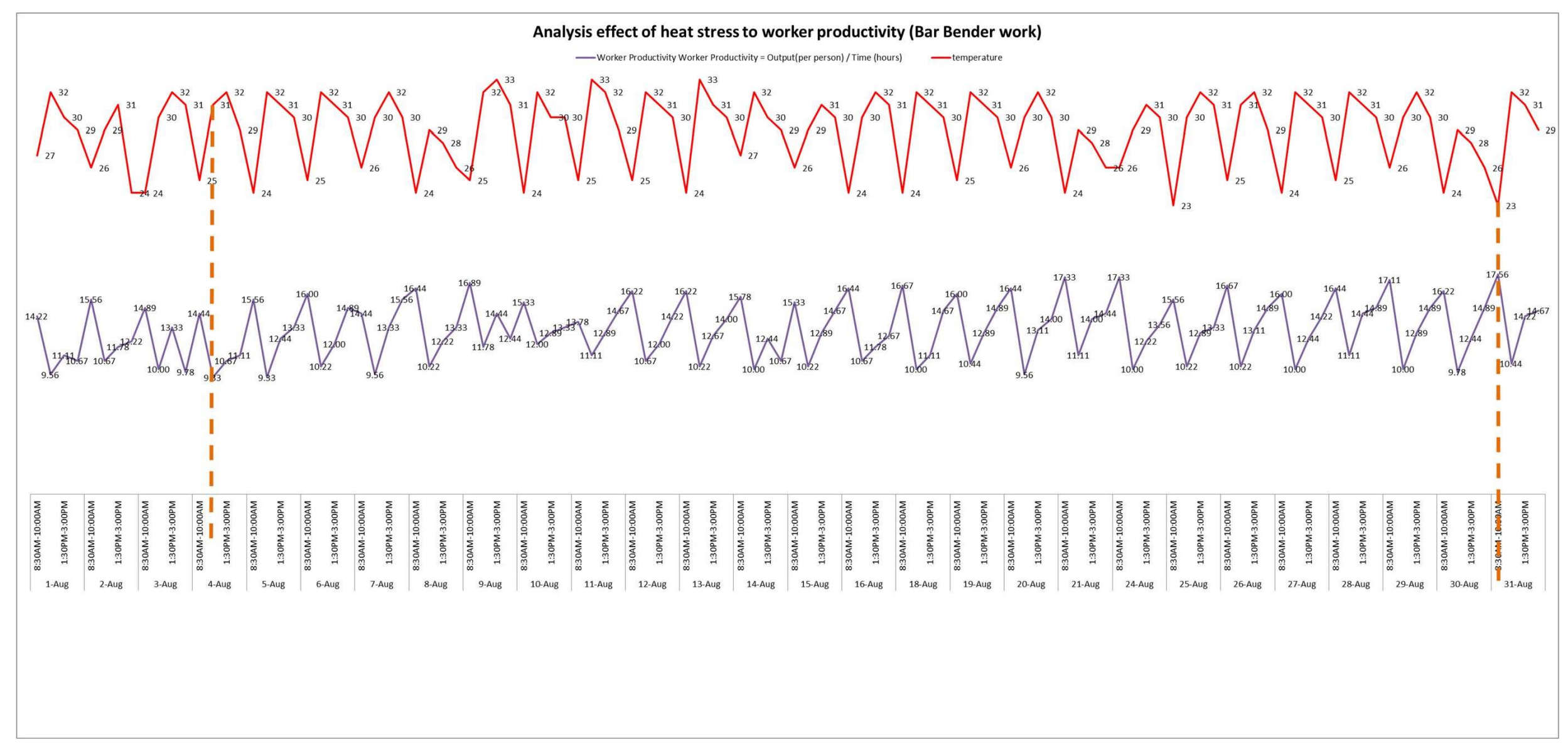

Figure 9. Analysis effect of heat stress to worker productivity (Bar bender) 


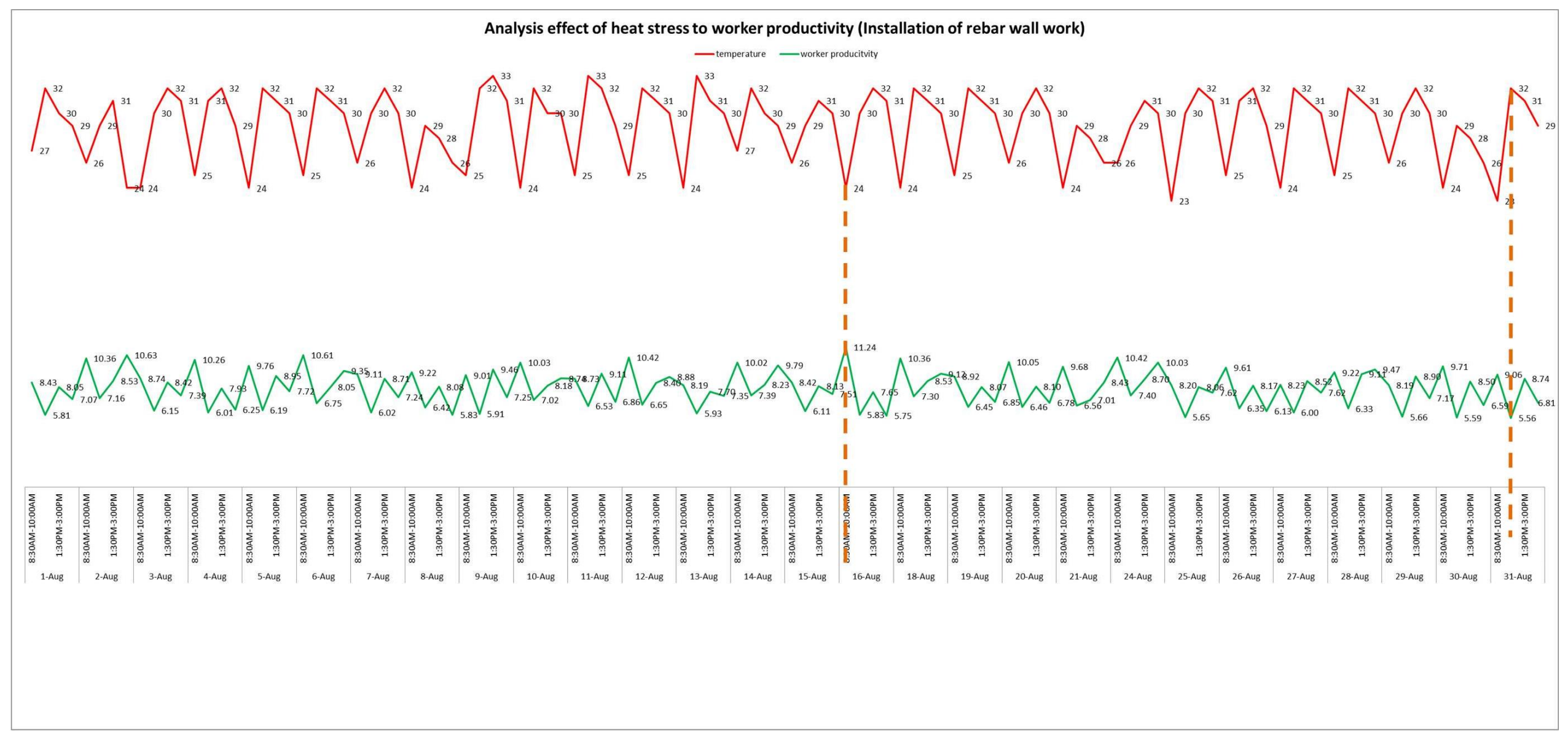

Figure 10. Analysis effect of heat stress to worker productivity (Installation of rebar wall) 


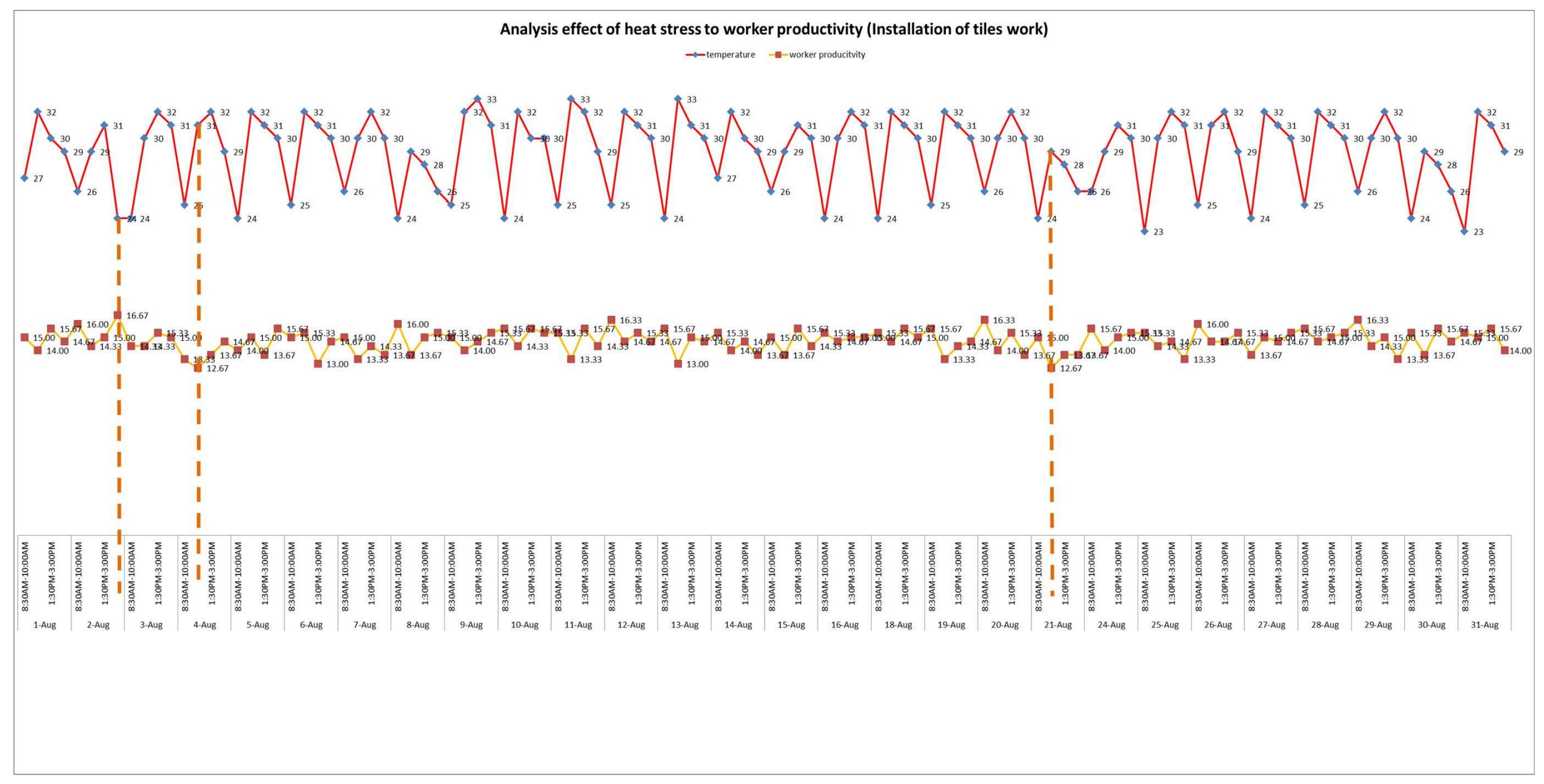

Figure 11. Analysis effect of heat stress to worker productivity (Installation of tiles) 


\subsubsection{Comparison Analysis of the Effect of Heat Stress on Worker Productivity between Installation of Tiles and Installation of Rebar Wall}

The effects of thermal stress can be seen in the above analysis of the three fields of tasks based on a decrease in worker productivity as the temperature rises. The lesser the worker productivity, the more heat stress there is.

The effect of heat stress on worker productivity during tile installation and rebar wall installation activities was compared. Because this construction site is a high-rise building, the tile installation is taking place within the structure while the rebar wall erection is taking place outside. As a result, when high temperatures arise, the worker who constructed the rebar wall is more vulnerable to heat stress than the worker who laid tiles in the building.

The month's high temperature is 33 degrees Celsius, which occurred on August 9, 2019. Installation rebar wall worker productivity is $5.04 \mathrm{~m}^{2} /$ hour, and installation tiles worker productivity is $5.28 \mathrm{~m}^{2} /$ hour as the temperature reaches its maximum. As a result, this could be attributed to the fact that outsiders are exposed to more heat stress than those inside structures. Heat stress in the workplace has an impact not only on the individual, but also on job efficiency and productivity, as well as the local economy [8].

\subsubsection{Optimum Work Pattern}

According to the research, the ideal period for site observation is between 8:30 and 10:00 a.m. Due to increased worker productivity than other time intervals, this time interval was deemed the best work pattern. This work pattern does not cause individuals to as much heat stress as the work pattern from 11:00 a.m. to 1:00 p.m. This work pattern does not cause individuals to as much exposure to heat stress as the work pattern from 11:00 a.m. to 1:00 p.m. The most crucial period for worker productivity is between 11:00 a.m. to 12:30 p.m. Workers become weary, and their productivity suffers as a result of the high temperatures. Finally, a two-time interval is used to consider the intermediate level of worker production. As a result, the working pattern should begin early to avoid heat stress.

According to prior study [9], in order to get ahead in any endeavour, all factors that affect productivity must be considered. Worker productivity was a factor in the project's total productivity. The criterion for worker productivity can be discovered in the literature review that is being analysed to find the best one. An interview with the site specialist was held in order to find the most suited one. Finally, output per unit time is the best formula for calculating worker productivity.

Heat stress affects all forms of worker, according to the findings. Furthermore, a comparison of two distinct types of work was carried out to determine the impact of heat stress on workers who were subjected to high and low levels of heat stress. Then, following a series of analyses, the best work pattern was discovered. According to current research [10], the percentage difference in daily injury claims per ${ }^{\circ} \mathrm{C}$ decrease in maximum daily temperature $(\max )$ just below threshold temperature $\left(37.7^{\circ} \mathrm{C}\right)$ can lead to productivity loss due to heat stress. Heat exhaustion is very well occupational health danger that can cause everything from pains to death. Malaysia's Department of Occupation Safety and Health adopted in articles 15(1) and 15(2) of the Occupational Safety and Health Act of 1994, employers and self-employed people are obligated to their employees (e). Machineries and Factories In 1970, there were Regulation 28(1) states that if the operation of any machinery or process produces excessive heat, an Inspector may demand those suitable provisions be made, and Regulation 28(2) states that if the Inspector believes the temperature in a factory or part thereof is excessively high, the Inspector may necessitate those suitable provisions be made. Regulation 28(3) additionally states that any building made entirely or partially of materials with higher coefficient of heat transfer that has been exposed to the sun's heat is prohibited. To the fullest extent practicable, providing and maintaining a safe and healthy working environment for employees should be prioritized [11].Occupational Health and Safety (OHS) has a positive effect on the performance of workers since this job is in an open location and involves a lot of manual works.

Employers should take heat stress management seriously. This circumstance can cut project time and expense at the same time. Because the optimum work pattern is adopted by employers, the worker's cost payment can be decreased due to less time spent on the job. Furthermore, if heat stress is ignored, the worker would be exposed to weariness, which would impair worker productivity. Choosing the best work schedule is an efficient way to boost productivity. Aside from that, the influence of this work benefits the surrounding area and helps the government plan for a progressive country.

\section{Conclusions}

Based on the overall study, all aspects that influence performance must be taken into account in order to succeed in any project. Worker productivity is a factor in the project's total productivity. As a result, worker productivity is critical to the project's success. The factors for worker productivity were discovered in the literature review, which was then assessed to find the best one. Finally, output per unit time is the best formula for calculating worker productivity. 
Table 4. Summary of Analysis

\begin{tabular}{|c|c|c|c|}
\hline $\begin{array}{c}\text { Criteria of Worker Productivity } \\
\text { Towards Successful Project } \\
\end{array}$ & & bour Productivity $=\frac{\text { Out }}{\text { Tin }}$ & \\
\hline \multirow[t]{3}{*}{ Type of Worker } & Bar Bender & Installation Rebar Wall & Installation Tiles \\
\hline & 8:30AM-10:00AM & 8:30AM-10:00AM & 8:30AM-10:00AM \\
\hline & 11:00AM-12:30PM & 11:00AM-12:30PM & 11:00AM-12:30PM \\
\hline \multirow{2}{*}{ Type of Working Pattern } & 1:30PM-3:00PM & 1:30PM-3:00PM & 1:30PM-3:00PM \\
\hline & 4:00PM-5:30PM & 4:00PM-5:30PM & 4:00PM-5:30PM \\
\hline $\begin{array}{c}\text { Maximum Worker Productivity In } 1 \\
\text { Month }\end{array}$ & 17.56 n.o.s/hour & $11.24 \mathrm{~m}^{2} /$ hour & 16.67 n.o.t/hour \\
\hline Date & 31st August 2019 & 16th August 2019 & 2nd August 2019 \\
\hline Working Pattern & 8:30am-10:00am & 8:30am-10:00am & 4:00pm-5:30pm \\
\hline Temperature & 23-degree celcius & 24-degree celcius & 24-degree celcius. \\
\hline Minimum Worker Productivity In 1 Month & 9,33 n.o.s/hour & $5.56 \mathrm{~m}^{2} /$ hour & 12.67 n.o.t/hour \\
\hline Date & 4th and 5th August 2019 & 31st August 2019 & 4th and 21st August 2019 \\
\hline Working Pattern & 11:00am-12:30am & 11:00am-12:30am & 11:00am-12:30am \\
\hline Temperature & 32-degree celcius. & 29-degree celcius. & 32 and 29 -degree celcius. \\
\hline
\end{tabular}

Next, one of the elements affecting worker productivity is heat stress. This condition is demonstrated in data analysis through the use of three different tasks to conduct line graph analysis. Heat stress affects all forms of worker, according to the findings. Furthermore, a comparison of two distinct types of work was carried out to determine the impact of heat stress on workers who were subjected to high and low levels of heat stress.

Employers should take heat stress management seriously. This circumstance can cut project time and expenses at the same time. Because the optimum work pattern is adopted by employers, the worker's cost payment can be decreased due to less time spent on the job. Choosing the best work schedule is an efficient way to boost productivity. Aside from that, the influence of this work benefits the surrounding area and helps the government plan for a progressive country.

\section{Acknowledgments}

This author would like to thank Universiti Teknologi MARA Cawangan Pulau Pinang for funded this research work.

\section{REFERENCES}

[1] W. Yi, C. Albert. Optimal Work Pattern for Construction Workers in Hot Weather: A Case Study in Hong Kong.
Journal of Computing in Civil Engineering, Vol. 29, No 5, 2015.

[2] Y. June-Seong, K. Yong-Woo, K. Ki-aeng, K. Bonsang. A suggested color scheme for reducing perception-related accidents on construction work sites. Accident; analysis and prevention, No. 48, 185-92, 2012.

[3] K. Lundgren, K. Kuklane, C. Gao, I. Holmer. Effects of Heat Stress on Working Populations when Facing Climate Change. Industrial Health, Vol. 51, No 1, pp. 3-15, 2013.

[4] C. Hart. Doing a Literature Review: Releasing the Social Science Research Imagination (SAGE Study Skills Series). Doing a Literature Review, 1998.

[5] A.M. Jarkas. Factors influencing worker productivity in Bahrain's construction industry. International Journal of Construction Management, Vol. 15, No 1, 94-108, 2015.

[6] Y. Li, C. Liu. Worker productivity measurement with variable returns to scale in Australia's construction industry, Architectural Science Review, 2012.

[7] V. Tran, J. Tookey. Worker productivity in the New Zealand construction industry: A thorough investigation. Australasian Journal of Construction Economics and Building, 2011.

[8] T. Kjellstrom, C. Freyberg, B. Lemke, M. Otto, D. Briggs. Estimating population heat exposure and impacts on working people in conjunction with climate change. Int. J. Biometeorol, 2017.

[9] K.A. Shamsuddin, C. Mohd Norzaimi, A. Ismail, \& M. Riduan bin Ibrahim. Investigation the Safety, Health and Environment (SHE) Protection in Construction Area. International Research Journal of Engineering and Technology (IRJET), 2015. 
[10] P. Acharya, B. Boggess, \& K. Zhang. Assessing Heat Stress and Health among Construction Workers in a Changing Climate: A Review. International Journal of Environmental Research and Public Health, Vol. 15, No 2, 247, 2018.

[11] Department of Safety and Health. Guidelines on Heat Stress Management at Workplace, 2016.
[12] F.Handoko, M. Wijayaningtyas, Imam H. A. Kusuma, S Hidayat, A. Ismail , Z. Abdullah, "The Occupational Health and Safety Effect on Rad Construction Worker Performance," Civil Engineering and Architecture, Vol. 8, No. 5, pp. 750 - 759, 2020. DOI: 10.13189/cea.2020.080502 